\title{
Agregados em um Latossolo sob sistema plantio direto e rotação de culturas
}

\author{
Rodrigo Arroyo Garcia(1) e Ciro Antonio Rosolem ${ }^{(2)}$
}

\begin{abstract}
(1)Embrapa Agropecuária Oeste, Rodovia BR 163, Km 253,6, Caixa Postal 661, CEP 79804-970 Dourados, MS. E-mail: rodrigo@cpao.embrapa.br (2)Universidade Estadual Paulista, Faculdade de Ciências Agronômicas, Departamento de Produção Vegetal/Agricultura, Rua José Barbosa de Barros, no 1.780, CEP 18610-307 Botucatu, SP. E-mail: rosolem@fca.unesp.br
\end{abstract}

Resumo - O objetivo deste trabalho foi avaliar a influência dos cultivos de outono-inverno e primavera, em sistema de plantio direto, nos agregados e matéria orgânica de um Latossolo. O experimento foi conduzido durante as safras 2006/2007, 2007/2008 e 2008/2009. No outono-inverno foram estabelecidas parcelas principais com braquiária (Urochloa ruziziensis), sorgo granífero (Sorghum bicolor) e sorgo consorciado com braquiária. Na primavera, foram cultivados, em subparcelas, milheto (Pennisetum glaucum), 'Cober Crop' (Sorghum bicolor x Sorghum sudanense), crotalária (Crotalaria juncea) ou pousio. A soja foi cultivada como safra de verão, o que totalizou 12 tratamentos. A massa de matéria seca e o crescimento radicular das plantas de cobertura da primavera foram determinados em 2006 e 2008. Foram coletadas amostras de solo nas camadas de $0-5$ e 5-10 cm, após o manejo das plantas de cobertura de primavera, no primeiro e terceiro anos agrícolas. Foram determinados o diâmetro médio ponderado, o diâmetro médio geométrico, o índice de estabilidade de agregados, os agregados maiores que $2 \mathrm{~mm}$, a matéria orgânica e os teores de carbono orgânico total nas amostras coletadas no terceiro ano. O milheto e 'Cober Crop' produziram maior quantidade de massa de matéria seca e maior crescimento radicular. A estruturação do solo melhorou com a rotação dos cultivos das plantas de cobertura antecedentes à safra de verão. O cultivo de 'Cober Crop' e milheto influenciou a formação de macroagregados nas camadas superficiais.

Termos para indexação: carbono, matéria orgânica, plantas de cobertura.

\section{Aggregates in a Rhodic Ferralsol under no-tillage and crop rotation}

\begin{abstract}
The objective of this work was to evaluate the influence of fall-winter and spring crops, cultivated under no-tillage system, on the aggregates and organic matter of a Rhodic Ferralsol. The experiment was performed in the 2006/2007, 2007/2008 and 2008/2009 growing seasons. Congo signal grass (Urochloa ruziziensis), grain sorghum (Sorghum bicolor) and sorghum mixed with brachiaria were cropped in the fall-winter to consist the main plots. In the spring, millet (Pennisetum glaucum), 'Cober Crop' (Sorghum bicolor x Sorghum sudanense) and Indian hemp (Crotalaria juncea) were cultivated as subplots as well as a fallow treatment. Soybean was cropped in the summer, totaling 12 treatments. Cover crop dry matter and root growth were evaluated in 2006 and 2008. Soil samples were taken from $0-5$ and 5-10 cm depths, after spring cover crops managing, in the first and third years. The mean weight diameter, geometric mean diameter, aggregate stability index, aggregates larger than $2 \mathrm{~mm}$, organic matter and total organic carbon levels were evaluated in the samples of the third year. Millet and 'Cober Crop' showed higher dry matter production and root growth. The soil aggregation was improved by cover crop rotations before the summer growing season. The cultivation of 'Cober Crop' and millet influenced the macroaggregate formation in the superficial layers.
\end{abstract}

Index terms: carbon, organic matter, cover crops.

\section{Introdução}

A qualidade do solo pode ser analisada segundo variáveis relacionadas à sua forma e à sua estabilidade e, entre as propriedades físicas do solo, a estrutura e a agregação estão entre os parâmetros mais sensíveis ao manejo (Stone \& Schlegel, 2010; Tavares Filho et al., 2010). A estrutura do solo pode ser definida como o arranjo das partículas primárias do solo, ou seja, das frações argila, silte e areia, que formam as partículas secundárias ou agregados, e a matéria orgânica tem papel fundamental nesse processo (Corrêa et al., 2009).

Em relação à formação e à estabilização dos microagregados, várias formas de ligação ocorrem concomitantemente. As macromoléculas húmicas 
apresentam grande quantidade de radicais orgânicos, que interagem de forma distinta com a superfície do mineral. Adicionalmente às ligações eletrostáticas e pontes de cátions, outras formas de atração ocorrem, como pontes de hidrogênio e forças de van der Waals (Bayer \& Mielniczuk, 2008). Outra categoria de compostos orgânicos importante na estabilização de agregados (microagregados) são os polissacarídeos. Os polissacarídeos do solo são mucilagens provenientes do metabolismo microbiano e da decomposição de raízes, resíduos vegetais e animais e da exsudação radicular. No entanto, os polissacarídeos provenientes do metabolismo microbiano têm maior efeito cimentante nos microagregados do solo, em razão do maior peso molecular desses compostos (Guerra et al., 2008).

Em relação à estabilidade dos macroagregados, formados a partir da união de microagregados, os componentes orgânicos mais importantes são as hifas de fungos e uma fração da matéria orgânica, com pequeno grau de decomposição, denominada de matéria orgânica leve ou matéria orgânica particulada. Esses componentes possuem efeito mecânico na agregação do solo (Corrêa, 2002).

Portanto, a matéria orgânica proveniente do crescimento radicular e do constante aporte de palha na superfície tem papel fundamental na melhoria das propriedades físicas do solo, pois acarreta maior agregação e, a partir desse efeito, indiretamente, são afetadas as demais características físicas como densidade, porosidade, aeração, capacidade de retenção e infiltração de água, entre outras, que são fundamentais à capacidade produtiva do solo (Imhoff, 2002).

No trabalho de Calonego \& Rosolem (2008), foram observados melhores índices de agregação do solo, em consequência da espécie cultivada no outono-inverno. $\mathrm{O}$ cultivo de triticale gerou maior quantidade de macroagregados no solo, em comparação ao tratamento com girassol. Isso pode estar relacionado à escolha de espécies vegetais com crescimento vigoroso e maior capacidade em adicionar carbono ao solo.

O objetivo do presente trabalho foi avaliar a influência dos cultivos de outono-inverno e primavera, em sistema de plantio direto, nos agregados e matéria orgânica de um Latossolo.

\section{Material e Métodos}

O experimento foi realizado na Faculdade de Ciências Agronômicas, da Universidade Estadual
Paulista, Botucatu, SP, nas safras agrícolas de 2006/2007, 2007/2008 e 2008/2009. A área está localizada a $22^{\circ} 49^{\prime} \mathrm{S}, 48^{\circ} 25^{\prime} \mathrm{W}$ e altitude de $786 \mathrm{~m}$. O clima da região, segundo classificação de Köppen, é do tipo Cwa, mesotérmico com inverno seco. O solo da área experimental tem relevo suave-ondulado e foi classificado como Latossolo Vermelho distroférrico de textura argilosa, conforme Santos et al. (2006). A área foi cultivada por sete anos, em sistema plantio direto (SPD), com a sucessão feijão/aveia-preta, em que feijão foi a cultura de verão, e a aveia-preta a de outono-inverno. Na Figura 1, estão apresentados os dados meteorológicos observados durante os anos agrícolas de 2006/2007 e 2008/2009, quando foram realizadas as coletas de amostras.

Em março de 2006, após a colheita do feijão e antes da demarcação das parcelas experimentais, foram abertas quatro trincheiras em locais representativos, escolhidos de maneira aleatória, para a coleta de amostras deformadas nas profundidades $0-5,5-10$, $10-20,20-40$ e $40-60 \mathrm{~cm}$, e não deformadas nas
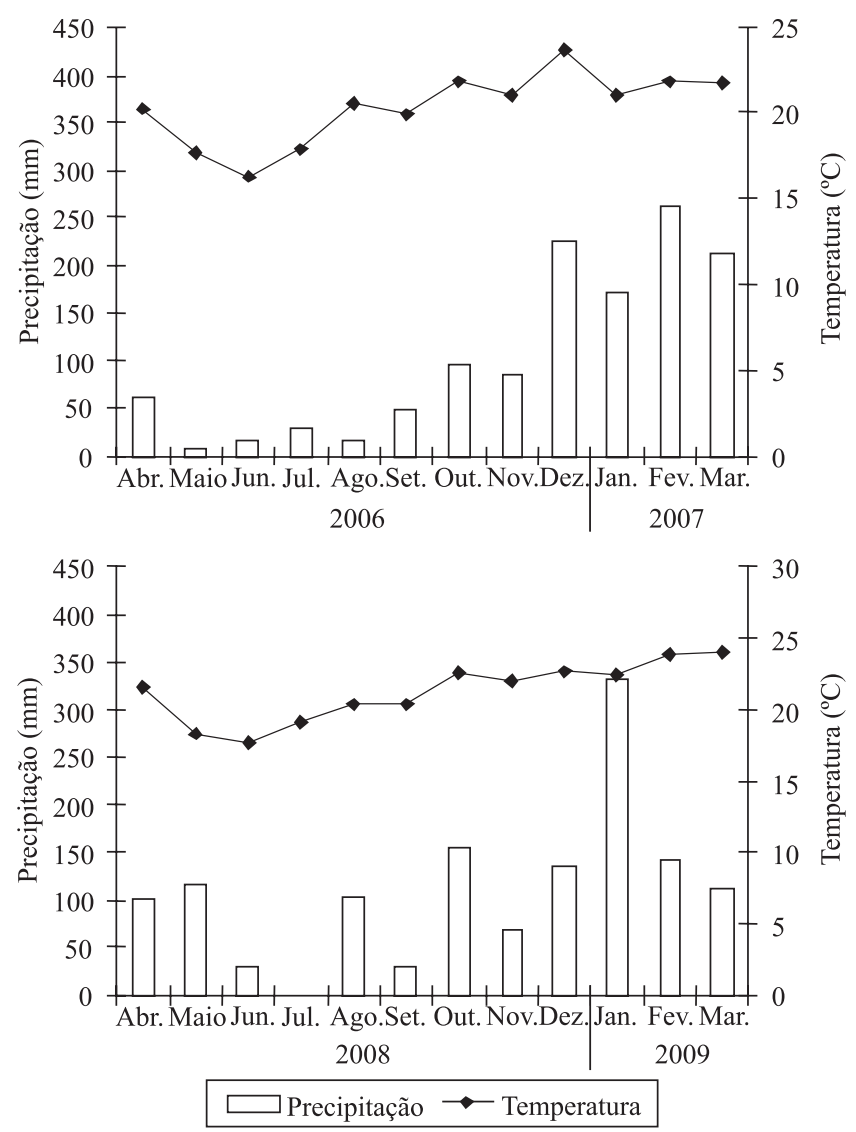

Figura 1. Dados meteorológicos observados nos anos agrícolas 2006/2007 e 2008/2009. 
profundidades $0-5,7,5-12,5,15-20,27,5-32,5$ e $47,5-52,5 \mathrm{~cm}$, com uso de anéis volumétricos. Todas as amostras foram avaliadas conforme as Recomendações técnicas para a cultura de soja na Região Central do Brasil (1997). Nas amostras deformadas, foram determinadas a granulometria e as análises químicas de rotina, para caracterizarem a fertilidade no perfil do solo, de acordo com procedimentos propostos por Raij et al. (2001). Nas amostras não deformadas, foram avaliadas a densidade do solo, a macroporosidade, a microporosidade e a porosidade total. Por ocasião da caracterização da área experimental, também foram coletados torrões de solo nas camadas de $0-5$ e 5-10 cm, para avaliação da estabilidade de agregados via úmida. Os resultados referentes à caracterização do solo estão apresentados nas Tabelas 1 e 2.

Os tratamentos foram constituídos por sorgo granífero, Sorghum bicolor (L.) Moench (S. vulgare Pers.), e braquiária, Urochloa ruziziensis (R. Germ.

Tabela 1. Caracterização dos atributos físicos do solo da área experimental ${ }^{(1)}$.

\begin{tabular}{|c|c|c|c|c|}
\hline \multirow{2}{*}{$\begin{array}{l}\text { Profundidade } \\
\quad(\mathrm{cm})\end{array}$} & \multicolumn{3}{|c|}{ Granulometria $\left(\mathrm{g} \mathrm{kg}^{-1}\right)$} & \multirow{2}{*}{$\begin{array}{l}\text { Textura do } \\
\text { solo }\end{array}$} \\
\hline & Areia & Argila & Silte & \\
\hline $0-10$ & 489 & 415 & 96 & Argilosa \\
\hline $10-20$ & 435 & 462 & 103 & Argilosa \\
\hline \multirow[t]{2}{*}{$20-40$} & 385 & 509 & 106 & Argilosa \\
\hline & $\begin{array}{l}\text { DMP } \\
(\mathrm{mm})\end{array}$ & $\begin{array}{l}\mathrm{DMG} \\
(\mathrm{mm})\end{array}$ & $\begin{array}{c}\text { Agregados }>2 \mathrm{~mm} \\
(\%)\end{array}$ & $\begin{array}{l}\text { IEA } \\
(\%) \\
\end{array}$ \\
\hline $0-5$ & 2,75 & 2,35 & 65 & 87,4 \\
\hline \multirow[t]{2}{*}{ 5-10 } & 2,57 & 2,18 & 54 & 85,0 \\
\hline & $\begin{array}{c}\text { Ds } \\
\left(\mathrm{Mg} \mathrm{m}^{-3}\right)\end{array}$ & $\begin{array}{c}\mathrm{Pt} \\
\left(\mathrm{m}^{3} \mathrm{~m}^{-3}\right)\end{array}$ & $\begin{array}{l}\text { Micro } \\
\left(\mathrm{m}^{3} \mathrm{~m}^{-3}\right)\end{array}$ & $\begin{array}{l}\text { Macro } \\
\left(\mathrm{m}^{3} \mathrm{~m}^{-3}\right)\end{array}$ \\
\hline $0-5$ & 1,35 & 0,43 & 0,33 & 0,10 \\
\hline $7,5-12,5$ & 1,41 & 0,41 & 0,34 & 0,07 \\
\hline $15-20$ & 1,39 & 0,41 & 0,32 & 0,09 \\
\hline $27,5-32,5$ & 1,25 & 0,45 & 0,32 & 0,13 \\
\hline $47,5-52,5$ & 1,25 & 0,45 & 0,33 & 0,12 \\
\hline
\end{tabular}

(1)DMP, diâmetro médio ponderado; DMG, diâmetro médio geométrico; IEA, índice de estabilidade de agregados; Ds, densidade aparente do solo; $\mathrm{Pt}$, porosidade total.
\& C. M. Evrard) Crins, cultivadas no outono-inverno, combinadas com espécies de cobertura: milheto (Pennisetum americanum (L.) Leeke), crotalária (Crotalaria juncea L.), 'Cober Crop' (Sorghum bicolor x Sorghum sudanense (Piper) Stapf) e pousio, conduzidos na primavera que antecedeu a cultura de verão, que foi a soja (Glycine $\max$ (L.) Merril).

Para o plantio de outono-inverno, primavera e verão utilizou-se uma semeadora modelo Personale-DRILL-13 (Semeato S.A Implementos Agrícolas, Passo Fundo, RS, Brasil), equipada com discos de corte de palha com 16" de diâmetro e com discos sulcadores defasados (13" e 14" de diâmetro) para as sementes. Os procedimentos descritos a seguir foram repetidos nos três anos agrícolas. Nos três anos, a semeadura de outono-inverno foi realizada no fim de março, a de primavera no início de setembro, e a de verão na primeira semana de dezembro.

No outono-inverno, as culturas foram semeadas com espaçamento entrelinhas de $17 \mathrm{~cm}$ com braquiária solteira e de $51 \mathrm{~cm}$ com sorgo solteiro e consorciado com braquiária. Na semeadura da braquiária, foram utilizados 2,5 $\mathrm{kg} \mathrm{ha}^{-1}$ de sementes puras viáveis. O sorgo foi semeado com $10 \mathrm{~kg} \mathrm{ha}^{-1}$ de sementes. Nas parcelas com sistema consorciado, as sementes da braquiária foram depositadas na caixa de adubo da semeadora, e foram distribuídas na mesma linha de semeadura do sorgo.

Logo após a colheita de outono-inverno, a área experimental foi manejada quimicamente, e as espécies de cobertura foram semeadas em 13 linhas espaçadas de $17 \mathrm{~cm}$. A semeadora foi regulada para uma distribuição de $12 \mathrm{~kg} \mathrm{ha}^{-1}$ de sementes de 'Cober Crop' e milheto e $25 \mathrm{~kg} \mathrm{ha}^{-1}$ de crotalária. No caso das subparcelas mantidas em pousio, aos 30 dias após a semeadura das espécies de cobertura, a área foi roçada para não ocorrer infestação de plantas daninhas no cultivo em sucessão. Após a dessecação, não foi utilizado manejo

Tabela 2. Caracterização dos atributos químicos do solo da área experimental ${ }^{(1)}$.

\begin{tabular}{lcccccccc}
\hline Profundidade $(\mathrm{cm})$ & $\begin{array}{c}\mathrm{pH} \\
\mathrm{CaCl}_{2}\end{array}$ & $\begin{array}{c}\mathrm{MO} \\
\left(\mathrm{g} \mathrm{dm}^{-3}\right)\end{array}$ & $\begin{array}{c}\mathrm{P}_{\text {resina }} \\
\left(\mathrm{mg} \mathrm{dm}^{-3}\right)\end{array}$ & $\mathrm{K}$ & $\mathrm{Ca}$ & $\begin{array}{c}\mathrm{Mg} \\
\mathrm{CTC}\end{array}$ & $\begin{array}{c}\mathrm{V} \\
(\%)\end{array}$ \\
\hline $0-5$ & 5,6 & 30 & 42 & 1,4 & 33 & 20 & 87 \\
$5-10$ & 5,0 & 25 & 8 & 0,5 & 21 & 15 & 70 \\
$10-20$ & 5,3 & 18 & 12 & 0,6 & 25 & 57 & 72 \\
$20-40$ & 4,2 & 16 & 4 & 0,3 & 8 & 6 & 113 \\
$40-60$ & 4,4 & 18 & 4 & 0,4 & 11 & 9 & 13 \\
\hline
\end{tabular}

${ }^{(1)} \mathrm{MO}$, materia orgânica; CTC, capacidade de troca de cátions; V, saturação por bases. 
mecânico da palhada, e os restos vegetais tiveram acamamento natural, com posterior semeadura da soja. A soja 'Embrapa 48' foi semeada em linhas espaçadas de $51 \mathrm{~cm}$, com distribuição de 18 sementes por metro (germinação de 90\%), e aplicados $370 \mathrm{~kg} \mathrm{ha}^{-1}$ do formulado 0-20-10. Utilizou-se o delineamento experimental de blocos ao acaso, com quatro repetições, em esquema de parcelas subdivididas. As parcelas foram cultivadas com braquiária, sorgo e braquiária consorciada com sorgo. Nas subparcelas, foi cultivado o milheto, o 'Cober Crop', a crotalária e o pousio. A soja foi cultivada como safra de verão em todas as parcelas, no total de 12 tratamentos.

Com o intuito de determinar a massa de matéria seca da parte aérea, das plantas cultivadas na primavera nos anos de 2006 e 2008, foram coletadas três subamostras, com gabarito de madeira medindo $0,5 \times 0,5 \mathrm{~m}$. As amostras de massa vegetal foram desidratadas em estufa de aeração forçada a $60^{\circ} \mathrm{C}$, por 72 horas, e posteriormente pesadas.

Foram coletadas amostras de raízes das espécies de cobertura, cultivadas na primavera nas profundidades de $0-5,5-10,10-20,20-40$ e 40-60 cm. As raízes foram amostradas no dia anterior à dessecação química, ou seja, junto com as coletas de fitomassa da parte aérea. As raízes foram amostradas na linha de semeadura, com quatro subamostras por unidade experimental, por meio de um trado do tipo caneca.

Após a lavagem das raízes, as amostras foram acondicionadas em recipientes de plástico, submersas em solução aquosa com $30 \%$ de álcool etílico, e armazenadas sob refrigeração a $2^{\circ} \mathrm{C}$. As amostras processadas e armazenadas foram encaminhadas a um "scanner" de leitura ótica Scanjet 4C/T HP (Hewlett Packard Co., Palo Alto, Ca, EUA), na resolução de 250 dpi, e tiveram suas imagens digitalizadas e analisadas com o programa "Win Mac Rhizo" versão 3.8-b (Regent Instruments Inc., Quebec, Canadá), para determinar a densidade de comprimento radicular (centímetro de raiz por centímetro cúbico de solo coletado), conforme Tennant (1975). Em seguida, as amostras de raízes foram colocadas em sacos de papel e secas em estufa de aeração forçada a $60^{\circ} \mathrm{C}$ por 48 horas, para determinação da massa da matéria seca.

Foram coletadas amostras de solo, após o manejo das plantas de cobertura de primavera, no primeiro e terceiro anos agrícolas, em dezembro de 2006 e 2008, respectivamente. No perfil exposto pelas trincheiras abertas, foram retirados, com o auxílio de espátula, torrões de solo com dimensões aproximadas de $5 \mathrm{~cm}$ de altura por $15 \mathrm{~cm}$ de comprimento e $10 \mathrm{~cm}$ de largura, nas profundidades de $0-5$ e $5-10 \mathrm{~cm}$. As amostras foram pré-selecionadas em um jogo de peneiras sobrepostas, em que as peneiras superior e inferior tinham malhas de 8 e $4 \mathrm{~mm}$, respectivamente. Para a avaliação da estabilidade dos agregados, utilizou-se a porção que passou pela malha de $8 \mathrm{~mm}$ e ficou retida na de $4 \mathrm{~mm}$. Cada amostra foi trabalhada em duplicata. Os agregados de solo pré-selecionados foram avaliados quanto à estabilidade via úmida, conforme Kemper \& Chepil (1965), que utilizaram o aparelho de oscilação vertical (Yoder, 1936). Foram quantificados os valores de diâmetro médio ponderado (DMP) e diâmetro médio geométrico (DMG). Calculou-se também o índice de estabilidade dos agregados (IEA), conforme Castro Filho et al. (1998). Quanto maior a percentagem de agregados grandes, retidos nas peneiras com malhas maiores, maior é o DMP. O DMG representa uma estimativa da classe de agregados de maior ocorrência. O IEA representa a medida de agregação total do solo e não considera a distribuição por classe de agregados. Quanto maior a quantidade de agregados menores que 0,105 mm, menor é o IEA.

Nas mesmas épocas de avaliação da estabilidade de agregados, ou seja, após o manejo das plantas de cobertura cultivadas na primavera em 2006 e 2008, determinaram-se os teores de matéria orgânica do solo nas camadas de $0-5$ e $5-10 \mathrm{~cm}$. No terceiro ano agrícola, as amostras utilizadas para determinação de matéria orgânica, com a metodologia de Raij et al. (2001), também tiveram os teores de carbono orgânico total (COT) avaliados via combustão seca por um analisador $\mathrm{C} / \mathrm{H} / \mathrm{N} / \mathrm{S}$ (Elementar Analysensysteme $\mathrm{GmbH}$, Hanau, Alemanha).

Os dados foram submetidos à análise de variância, e as médias foram comparadas pelo teste $\mathrm{t}$, a $5 \%$ de probabilidade. No terceiro ano agrícola, foram efetuados testes de correlação entre os teores de carbono orgânico total e os parâmetros de agregação do solo.

\section{Resultados e Discussão}

A caracterização do solo, por ocasião do início do experimento, evidencia condições restritivas ao crescimento das plantas, com porosidade de aeração inferior a $10 \%$ nas camadas mais superficiais, e a percentagem de agregados maiores que $2 \mathrm{~mm}$ também evidencia a baixa agregação do solo (Tabela 1). 
Nas duas avaliações de massa de matéria seca produzida pelas plantas de cobertura de primavera (2006 e 2008), as gramíneas apresentaram produção de massa muito superior à da crotalária (Tabela 3). No caso do pousio, foi considerada nula a produção de massa de matéria seca. A maior produção de massa de matéria seca das espécies $\mathrm{C}_{4}$ (milheto e 'Cober Crop') justifica-se pela maior eficiência fisiológica no aproveitamento da energia luminosa em relação às plantas $\mathrm{C}_{3}$ (crotalária), e pela menor necessidade de nitrogênio $(\mathrm{N})$ para a formação dos complexos enzimáticos de fixação do $\mathrm{CO}_{2}$, com maior sobra de $\mathrm{N}$ para a formação de novos tecidos (Taiz \& Zeiger, 2002; Rosolem et al., 2005).

As plantas de cobertura tiveram diferentes potenciais na exploração do perfil do solo, nos dois anos de experimento (Figura 2). Para as duas variáveis analisadas do sistema radicular (densidade de comprimento radicular e massa de matéria seca de raízes), as diferenças entre as espécies foram constatadas até a camada de $40-60 \mathrm{~cm}$ de profundidade. Como era esperado, a produção de raízes nas condições de pousio foi menor. As diferenças são mais evidentes nas camadas superficiais do solo, em que as rotações com o cultivo de 'Cober Crop' ou milheto apresentaram maior crescimento radicular. Isso é desejável em um solo conduzido em SPD, em que as camadas compactadas são mais superficiais, em razão da ausência de mobilização do solo (Pedrotti et al., 2001).

No primeiro ano de avaliação da estabilidade de agregados, o cultivo das plantas de cobertura, antecedente à coleta das amostras, melhorou alguns parâmetros avaliados, como o DMP e a proporção de agregados maiores que $2 \mathrm{~mm}$ (Tabela 4). Em contrapartida, o IEA não foi influenciado pelos tratamentos. A melhor estruturação do solo restringiuse à profundidade de $0-5 \mathrm{~cm}$. Para o DMP, as três espécies utilizadas como plantas de cobertura foram superiores ao pousio. Quanto à proporção de agregados

Tabela 3. Produção de massa de matéria seca $\left(\mathrm{kg} \mathrm{ha}^{-1}\right)$ das plantas de cobertura cultivadas na primavera, nos anos agrícolas de 2006 e 2008.

\begin{tabular}{lcc}
\hline Tratamento & 2006 & 2008 \\
\hline 'Cober Crop' & 5.115 & 10.350 \\
Crotalária & 1.718 & 4.629 \\
Milheto & 4.804 & 12.761 \\
Pousio & 0 & 0 \\
\hline
\end{tabular}

maiores que $2 \mathrm{~mm}$, o milheto foi similar ao 'Cober Crop', porém proporcionou agregados maiores em comparação à leguminosa. Segundo Hakanson et al. (1988), as plantas de cobertura com elevada capacidade de fixação de carbono e que também possuem sistema radicular volumoso e agressivo podem trazer benefícios na estruturação do solo, mesmo em curtos intervalos de cultivo. Isso pode ser constatado pela maior produção de massa de matéria da parte aérea e crescimento radicular das gramíneas de cobertura 'Cober Crop' e milheto, no primeiro ano de condução do experimento (Tabela 3 e Figura 2).

Quanto à análise da estabilidade de agregados, após o terceiro ano de rotações de culturas, observaram-se efeitos positivos das espécies vegetais nos $10 \mathrm{~cm}$ iniciais do perfil do solo (Tabela 5). As espécies conduzidas no outono-inverno diferiram consideravelmente. Para a camada de $0-5 \mathrm{~cm}$, o sistema consorciado entre braquiária e sorgo proporcionou maior DMP, e na avaliação do DMG, o sistema integrado foi superior à cultura granífera e similar à forrageira solteira. $\mathrm{Na}$ segunda camada de solo avaliada $(5-10 \mathrm{~cm})$, os agregados maiores que $2 \mathrm{~mm}$ sofreram influência parecida, em razão da presença da forrageira, independentemente da modalidade de cultivo.

As gramíneas de cobertura de primavera ('Cober Crop' e milheto) proporcionaram maior efeito agregante, nos $10 \mathrm{~cm}$ de solo avaliados, três anos após o cultivo dessas espécies (Tabela 4). Com esses resultados foi demonstrado que, além da ausência de revolvimento do solo preconizada pelo SPD, a manutenção de um considerável aporte de resíduos vegetais na superfície do solo, somada ao contínuo crescimento radicular propiciado pelo cultivo de plantas, é fundamental na melhoria e manutenção de uma boa agregação do solo. Para Huang et al. (2010), a aplicação de quantidades mais elevadas de resíduos orgânicos via adubos verdes, na presença ou ausência de fertilizantes inorgânicos, influenciou a maior agregação do solo, com a formação de grande quantidade de macroagregados.

A quantidade de restos vegetais na superfície do solo tem grande influência na maior agregação do solo, pois mesmo que não haja revolvimento da camada arável no SPD, a mobilização da camada superficial, no processo de semeadura, atua na incorporação de quantidade considerável de resíduos vegetais e influencia a maior agregação dos constituintes sólidos do solo nessas camadas superficiais. Portanto, a maior produção de massa de gramíneas de cobertura, ao longo dos anos 
(Tabela 2 e Figura 2), influenciou fortemente a estrutura do solo, avaliada pela estabilidade de agregados.

A agregação do solo também pode ter seu efeito acelerado pela exploração radicular que, no processo de crescimento, promove a aproximação das partículas à medida que as raízes exercem pressão sobre as partículas minerais no seu avanço pelo espaço poroso. A absorção de água pelas raízes também causa secamento na região adjacente, o que promove aumento na força de coesão entre as partículas (Zonta et al., 2006). No trabalho de Calonego \& Rosolem (2008), os autores atribuem a maior agregação do solo às características do sistema radicular do triticale cultivado no outono-inverno, em comparação ao girassol.
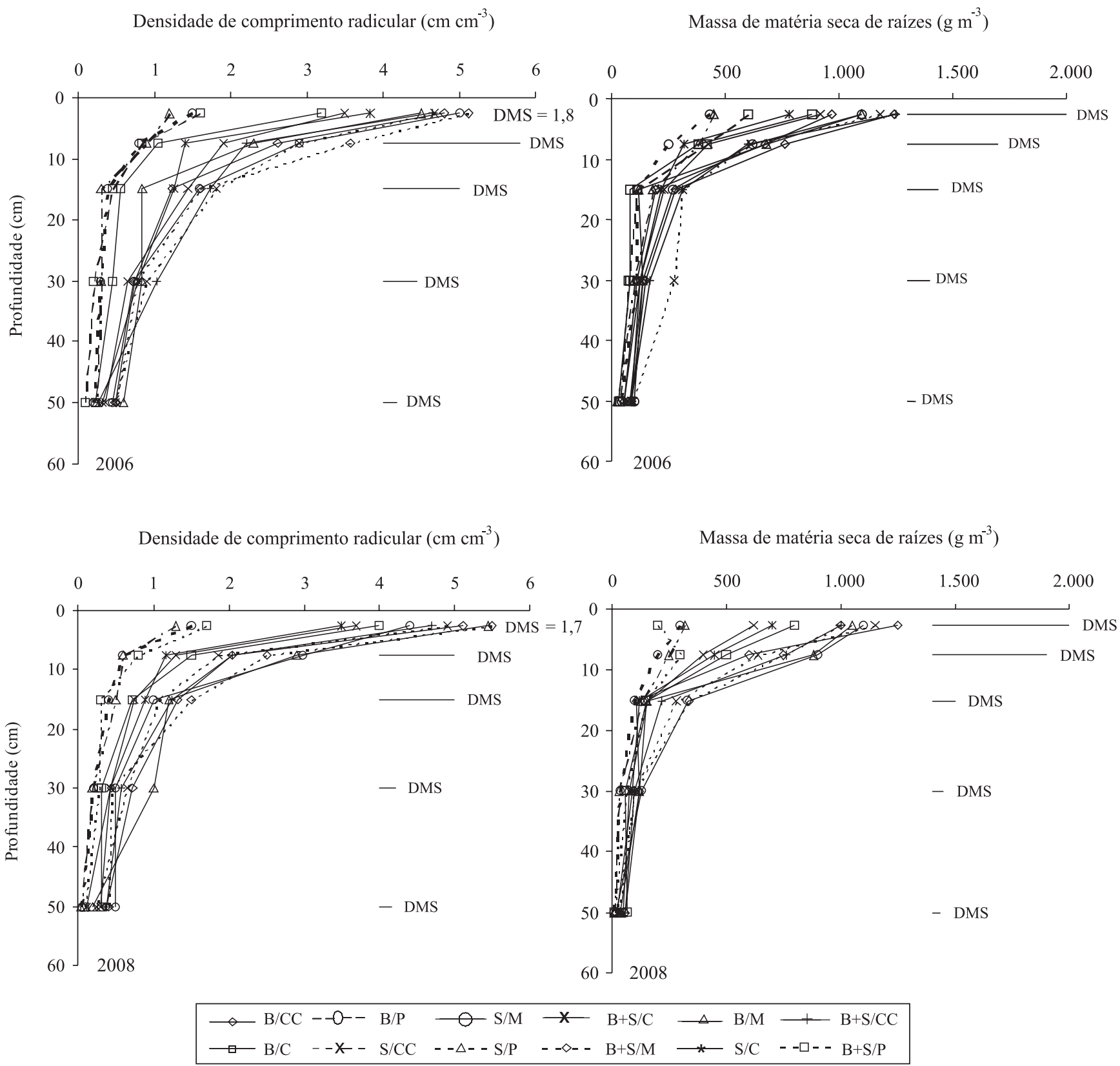

Figura 2. Densidade de comprimento radicular e massa de matéria seca de raízes, coletadas por ocasião do manejo das espécies de cobertura conduzidas na primavera, nas diferentes rotações de culturas, em 2006 e 2008. B, braquiária; $\mathrm{S}$, sorgo; B+S: braquiária + sorgo; CC, 'Cober Crop'; C, crotalária; M, milheto; $\mathrm{P}$, pousio. DMS, diferença mínima significativa. 
Segundo Mielniczuk (1999), a maior densidade de raízes das monocotiledôneas, em relação às dicotiledôneas, e a distribuição mais uniforme do sistema radicular favorecem a distribuição dos exsudados, os quais apresentam efeito aglutinador dos constituintes sólidos do solo. Além do mais, a maior quantidade de raízes serve como maior disponibilidade de substrato para a atividade de microrganismos, que têm papel fundamental na liberação de polissacarídeos de origem microbiana, com maior efeito agregante no solo (Bayer \& Mielniczuk, 2008). De acordo com as características do crescimento de suas raízes, a braquiária e as coberturas de primavera 'Cober Crop' e milheto, proporcionaram, em geral, melhorias em alguns parâmetros de agregação do solo como DMP, DMG e agregados maiores que $2 \mathrm{~mm}$, até a profundidade de $10 \mathrm{~cm}$, e os cultivos de primavera geraram

Tabela 4. Diâmetro médio ponderado (DMP), diâmetro médio geométrico (DMG), agregados maiores que $2 \mathrm{~mm}$ (A $>2 \mathrm{~mm}$ ) e índice de estabilidade de agregados (IEA), nas camadas do solo 0-5 e 5-10 cm, em razão dos cultivos de outono-inverno e primavera, após manejo das plantas de cobertura, em 2006.

\begin{tabular}{|c|c|c|c|c|}
\hline Tratamento & $\mathrm{DMP}(\mathrm{mm})$ & DMG $(\mathrm{mm})$ & $\mathrm{A}>2 \mathrm{~mm}(\%)$ & IEA $(\%)$ \\
\hline & \multicolumn{4}{|c|}{ Outono-inverno $(0-5 \mathrm{~cm})$} \\
\hline Braquiária (B) & 2,90 & 2,36 & 72,56 & 89,72 \\
\hline Sorgo (S) & 2,83 & 2,41 & 70,56 & 89,15 \\
\hline$\underline{\mathrm{S}+\mathrm{B}}$ & 2,88 & 2,53 & 71,25 & 89,85 \\
\hline \multirow[t]{2}{*}{ CV (\%) } & 7,85 & 11,47 & 4,40 & 11,11 \\
\hline & \multicolumn{4}{|c|}{ Primavera $(0-5 \mathrm{~cm})$} \\
\hline 'Cober Crop' & $2,96 a$ & 2,46 & $72,08 \mathrm{ab}$ & 90,54 \\
\hline Crotalária & $2,89 \mathrm{a}$ & 2,35 & $71,00 \mathrm{~b}$ & 90,10 \\
\hline Milheto & $2,97 \mathrm{a}$ & 2,49 & $75,83 \mathrm{a}$ & 91,50 \\
\hline Pousio & $2,68 \mathrm{~b}$ & 2,31 & $66,17 \mathrm{c}$ & 86,17 \\
\hline \multirow[t]{2}{*}{ CV (\%) } & 9,12 & 10,96 & 7,55 & 5,85 \\
\hline & \multicolumn{4}{|c|}{ Outono-inverno $(5-10 \mathrm{~cm})$} \\
\hline Braquiária (B) & 2,68 & 2,19 & 65,00 & 90,32 \\
\hline Sorgo (S) & 2,57 & 2,09 & 63,18 & 85,75 \\
\hline $\mathrm{S}+\mathrm{B}$ & 2,64 & 2,21 & 68,29 & 89,12 \\
\hline \multirow[t]{2}{*}{ CV (\%) } & 5,89 & 18,41 & 13,00 & 9,25 \\
\hline & \multicolumn{4}{|c|}{ Primavera $(5-10 \mathrm{~cm})$} \\
\hline 'Cober Crop' & 2,79 & 2,24 & 66,67 & 88,88 \\
\hline Crotalária & 2,69 & 2,23 & 67,50 & 91,18 \\
\hline Milheto & 2,77 & 2,35 & 62,75 & 91,19 \\
\hline Pousio & 2,63 & 2,09 & 63,92 & 84,00 \\
\hline CV (\%) & 6,45 & 11,64 & 7,66 & 8,15 \\
\hline
\end{tabular}

benefícios mais rápidos, ou seja, logo no primeiro ano do experimento (Tabelas 3 e 4). Com a maior agregação, além da maior proteção do solo contra agentes desagregantes (Severiano et al., 2008), outros parâmetros do solo relacionados diretamente ao crescimento das plantas podem ser afetados positivamente, como a resistência à penetração e o movimento de água e gases no perfil.

De acordo com os resultados obtidos por Oliveira et al. (2004), há correlação significativa entre o aumento no teor de matéria orgânica e o aumento da estabilidade de agregados até $0,10 \mathrm{~m}$ de profundidade. No entanto, no presente trabalho, os teores de matéria orgânica do solo não foram afetados pelos cultivos de outono-inverno e primavera, mesmo decorridos três anos do início do experimento (Tabela 6). Em contrapartida, no terceiro ano, houve tendência de acréscimo da matéria orgânica pelas plantas

Tabela 5. Diâmetro médio ponderado (DMP), diâmetro médio geométrico (DMG), agregados maiores que $2 \mathrm{~mm}$ (A $>2 \mathrm{~mm}$ ) e índice de estabilidade de agregados (IEA), nas camadas do solo $0-5$ e 5-10 cm, em razão dos cultivos de outono-inverno e primavera, após manejo das plantas de cobertura, em 2008.

\begin{tabular}{lcccc}
\hline Tratamento & DMP (mm) & DMG $(\mathrm{mm})$ & $\mathrm{A}>2 \mathrm{~mm}(\%)$ & IEA (\%) \\
\hline Braquiária (B) & $3,10 \mathrm{~b}$ & $2,70 \mathrm{ab}$ & 72,70 & 90,70 \\
Sorgo (S) & $3,18 \mathrm{~b}$ & $2,58 \mathrm{~b}$ & 71,63 & 89,99 \\
S+B & $3,43 \mathrm{a}$ & $2,79 \mathrm{a}$ & 72,06 & 90,15 \\
\hline CV (\%) & 7,20 & 5,73 & 9,88 & 8,12 \\
\hline \multicolumn{5}{c}{ Primavera $(0-5 \mathrm{~cm})$} \\
'Cober Crop' & $3,32 \mathrm{a}$ & 2,73 & $77,18 \mathrm{a}$ & 91,45 \\
Crotalária & $3,15 \mathrm{~b}$ & 2,68 & $74,75 \mathrm{a}$ & 90,18 \\
Milheto & $3,39 \mathrm{a}$ & 2,69 & $74,67 \mathrm{a}$ & 90,98 \\
Pousio & $3,04 \mathrm{~b}$ & 2,59 & $65,91 \mathrm{~b}$ & 88,50 \\
\hline CV (\%) & 8,39 & 7,82 & 5,63 \\
\hline \multicolumn{5}{c}{ Outono-inverno $(5-10 \mathrm{~cm})$} \\
Braquiária (B) & 2,94 & 2,63 & $73,56 \mathrm{a}$ & 90,96 \\
Sorgo (S) & 2,89 & 2,55 & $67,25 \mathrm{~b}$ & 88,29 \\
S+B & 3,01 & 2,61 & $74,88 \mathrm{a}$ & 91,85 \\
\hline CV (\%) & 7,79 & 8,65 & 8,79 \\
\hline \multicolumn{5}{c}{ Primavera $(5-10 \mathrm{~cm})$} \\
'Cober Crop' & $3,08 \mathrm{a}$ & 2,62 & $78,33 \mathrm{a}$ & 89,50 \\
Crotalária & $2,84 \mathrm{~b}$ & 2,60 & $68,00 \mathrm{~b}$ & 90,29 \\
Milheto & $2,98 \mathrm{a}$ & 2,61 & $77,67 \mathrm{a}$ & 90,42 \\
Pousio & $2,80 \mathrm{~b}$ & 2,49 & $63,17 \mathrm{~b}$ & 89,50 \\
\hline CV (\%) & 5,99 & 9,23 & 6,25 & 8,93 \\
\hline (1)Médias seguidas de letras iguais, nas colunas, não diferem entre si pelo \\
teste t, a 5\% de probabilidade.
\end{tabular}

Pesq. agropec. bras., Brasília, v.45, n.12, p.1489-1498, dez. 2010 
de cobertura de primavera, nas camadas de $0-5$ e 5-10 cm, com probabilidade do teste $F$ de cerca de 6 e $8 \%$, respectivamente. Em muitos casos, alterações nos estoques de matéria orgânica levam muitos anos para serem detectados, como no trabalho de Blanco-Canqui et al. (2010), em que as rotações de culturas e os sistemas de preparo do solo, após 33 anos de experimento, tiveram grandes efeitos nos atributos físico-hídricos, com atuação menos considerável nos valores da matéria orgânica do solo.

Por ocasião da caracterização da área experimental, os teores de matéria orgânica nas camadas de 0-5

Tabela 6. Teores de matéria orgânica $\left(\mathrm{g} \mathrm{dm}^{-3}\right)$ nas camadas do solo 0-5 e 5-10 cm, em razão dos cultivos de outono-inverno e primavera, após o manejo das plantas de cobertura, em 2006 e 2008.

\begin{tabular}{lccccc}
\hline Tratamento & \multicolumn{2}{c}{2006} & & \multicolumn{2}{c}{2008} \\
\cline { 2 - 3 } \cline { 5 - 6 } & $0-5 \mathrm{~cm}$ & $5-10 \mathrm{~cm}$ & & $0-5 \mathrm{~cm}$ & $5-10 \mathrm{~cm}$ \\
\hline \multirow{4}{*}{ Braquiária (B) } & 29,46 & 26,23 & & 33,25 & 28,88 \\
Sorgo (S) & 30,39 & 26,80 & & 33,65 & 28,41 \\
S+B & 29,43 & 26,55 & & 33,66 & 28,12 \\
\hline CV (\%) & 14,12 & 11,28 & 12,25 & 20,09 \\
\hline \multicolumn{5}{c}{ Cotono-inverno } \\
'Cober Crop' & 30,42 & 26,67 & 35,66 & 29,25 \\
Crotalária & 28,76 & 26,65 & 34,62 & 28,93 \\
Milheto & 30,70 & 27,67 & & 34,33 & 29,33 \\
Pousio & 28,65 & 26,40 & 32,27 & 27,40 \\
\hline CV (\%) & 12,84 & 13,15 & 18,06 & 17,14 \\
\hline
\end{tabular}

Tabela 7. Carbono orgânico total $\left(\mathrm{g} \mathrm{kg}^{-1}\right)$ nas camadas do solo 0-5 e 5-10 cm, em razão dos cultivos de outono-inverno e primavera, após o manejo das plantas de cobertura em 2008.

\begin{tabular}{lcc}
\hline Tratamento & $0-5 \mathrm{~cm}$ & $5-10 \mathrm{~cm}$ \\
\hline \multicolumn{3}{c}{ Outono-inverno } \\
Braquiária (B) & 19,29 & 16,09 \\
Sorgo (S) & 19,02 & 15,22 \\
S+B & 19,67 & 16,88 \\
\hline CV (\%) & 4,98 & 4,89 \\
\hline \multicolumn{3}{c}{ Primavera } \\
'Cober Crop' & $20,42 \mathrm{a}$ & $16,90 \mathrm{a}$ \\
Crotalária & $20,15 \mathrm{a}$ & $14,30 \mathrm{~b}$ \\
Milheto & $19,95 \mathrm{a}$ & $18,10 \mathrm{a}$ \\
Pousio & $15,37 \mathrm{~b}$ & $13,99 \mathrm{~b}$ \\
\hline CV (\%) & 5,04 & 4,65 \\
\hline (1) Médias seguidas de letras iguais, nas colunas, não diferem entre si pelo \\
teste t, a 5\% de probabilidade.
\end{tabular}

Pesq. agropec. bras., Brasília, v.45, n.12, p.1489-1498, dez. 2010 e 5-10 $\mathrm{cm}$ de profundidade foram de 30 e $25 \mathrm{~g} \mathrm{dm}^{-3}$ (Tabela 2), respectivamente e, apesar de não terem sido feitas comparações dos tratamentos ao longo dos anos com a análise inicial do solo, observou-se que a matéria orgânica foi incrementada até o final do experimento, pois os teores ultrapassaram $32 \mathrm{~g} \mathrm{dm}^{-3}$, na camada mais superficial do solo, em todos os tratamentos (Tabela 6). Os índices de agregação do solo também foram melhorados com o decorrer do experimento, com valores superiores aos constatados na caracterização do solo (Tabelas 1, 4 e 5).

No terceiro ano de experimento, o cultivo de 'Cober Crop', milheto e crotalária, na primavera, acrescentou à camada de $0-5 \mathrm{~cm}$ cerca de $1,0,68 \mathrm{e}$ $0,70 \mathrm{Mg} \mathrm{ha}^{-1}$ de matéria orgânica, respectivamente, em comparação ao solo mantido em pousio (Tabela 6). Essas quantidades são consideráveis e podem influenciar os atributos físicos do solo, o que de fato deve ter ocorrido, conforme análise da estabilidade de agregados no terceiro ano agrícola (Tabela 5).

De acordo com os teores de carbono orgânico, determinados via combustão seca no terceiro ano agrícola, o cultivo das plantas de cobertura de primavera elevou os teores de carbono na camada de $0-10 \mathrm{~cm}$ de profundidade (Tabela 7). Esse fato pode ser atribuído aos diferentes métodos utilizados na avaliação de carbono (Rheinheimer et al., 2008).

Os teores de carbono orgânico, determinados no terceiro ano agrícola, correlacionaram-se positivamente com alguns parâmetros relacionados à estrutura do solo (Figura $3 \mathrm{~A}$ e C). Esses efeitos foram detectados até a camada de 5-10 cm, em que o aumento dos teores de carbono orgânico proporcionou aumento na percentagem de agregados maiores que $2 \mathrm{~mm}$ (Figura $3 \mathrm{C}$ ). Portanto, os maiores teores de carbono orgânico nas camadas superficiais, em razão do cultivo de plantas de cobertura (Tabela 7), com maior destaque para as gramíneas, foram responsáveis pela maior agregação do solo, avaliada pelo diâmetro médio ponderado e macroagregados. Esses dados se assemelham aos obtidos por Salton et al. (2008), em que foi observada estreita relação entre a estabilidade dos agregados e o teor de carbono orgânico total do solo. Segundo os autores, a formação de macroagregados parece estar relacionada à presença de raízes, que são mais abundantes sob pastagem de gramíneas. 

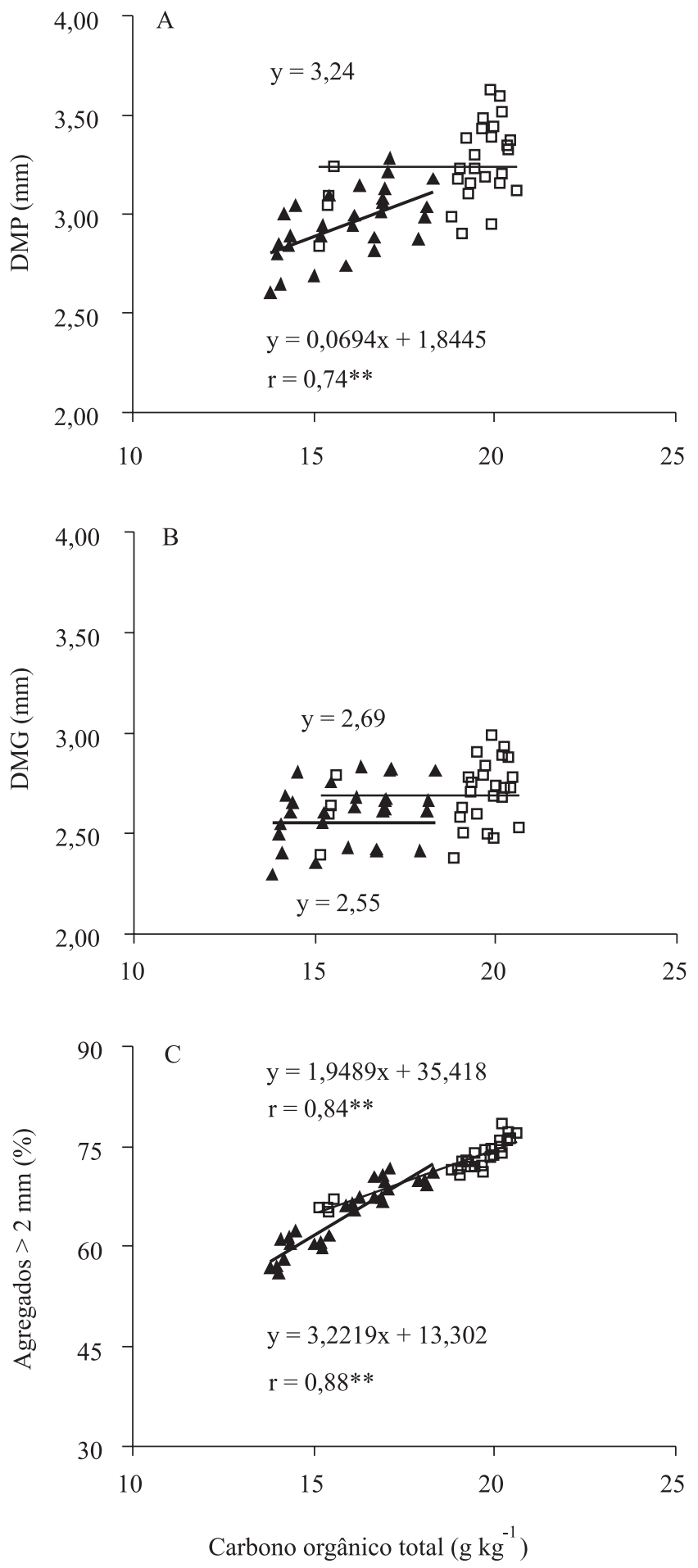

Figura 3. Correlação entre os teores de carbono orgânico total e os valores de diâmetro médio ponderado (DMP), diâmetro médio geométrico (DMG) e proporção de agregados maiores que $2 \mathrm{~mm}$, nas camadas de $0-5$ e $5-10 \mathrm{~cm}$, três anos após diferentes cultivos de outono-inverno e primavera. $\square$, $0-5 \mathrm{~cm} ; \boldsymbol{\Lambda}, 5-10 \mathrm{~cm}$. **Significativo a $1 \%$ de probabilidade pelo teste $\mathrm{t}$.

\section{Conclusões}

1. A maior produção de massa de matéria seca e o crescimento radicular das gramíneas de cobertura influenciam a maior agregação do solo nas camadas superficiais.

2. O cultivo de planta de cobertura na primavera, antecedente à soja, proporciona maior efeito na agregação do solo do que as espécies conduzidas no outono-inverno.

3. O cultivo de gramíneas de cobertura, como 'Cober Crop' e milheto, proporciona maior formação de macroagregados nas camadas superficiais.

\section{Agradecimentos}

Ao Dr. Yuncong Li, pelo auxílio nas análises de carbono orgânico na Universidade da Flórida; à Fundação de Amparo à Pesquisa do Estado de São Paulo, por concessão de bolsa.

\section{Referências}

BAYER, C.; MIELNICZUK, J. Dinâmica e função da matéria orgânica. In: SANTOS, G. deA.; SILVA, L.S. da; CANELLAS, L.P.; CAMARGO, F.A. de O. (Ed.). Fundamentos da matéria orgânica do solo: ecossistemas tropicais e subtropicais. 2.ed. Porto Alegre: Metrópole, 2008. p.7-18.

BLANCO-CANQUI, H.; STONE, L.R.; STAHLMAN, P.W. Soil response to long-term cropping systems on an Argiustoll in the central Great Plains. Soil Science Society of America Journal, v.74, p.602-611, 2010.

CALONEGO, J.C.; ROSOLEM, C.A. Estabilidade de agregados do solo após manejo com rotações de culturas e escarificação. Revista Brasileira de Ciência do Solo, v.32, p.1399-1407, 2008.

CASTRO FILHO, C.; MUZILli, O.; PODANOSCHI, A.L. Estabilidade dos agregados e sua relação com o teor de carbono orgânico num Latossolo Roxo distrófico, em função de sistemas de plantio, rotações de culturas e métodos de preparo de amostras. Revista Brasileira de Ciência do Solo, v.22, p.527-538, 1998.

CORRÊA, J.C. Efeito de sistemas de cultivo na estabilidade de agregados de um Latossolo Vermelho-Amarelo em Querência, MT. Pesquisa Agropecuária Brasileira, v.37, p.203-209, 2002.

CORRÊA, J.C.; BULL, L.T.; CRUSCIOL, C.A.C.; MORAES, M.H. Alteração de atributos físicos em Latossolo com aplicação superficial de escória de aciaria, lama cal, lodos de esgoto e calcário. Revista Brasileira de Ciência do Solo, v.33, p.263-272, 2009.

GUERRA, J.G.M.; SANTOS, G. de A.; SILVA, L.S. da; CAMARGO, F.A. de O. Macromoléculas e substâncias húmicas. In: SANTOS, G. de A.; SILVA, L.S. da; CANELLAS, L.P.; CAMARGO, F.A. de O. (Ed.). Fundamentos da matéria orgânica do solo: ecossistemas tropicais e subtropicais. 2.ed. Porto Alegre: Metrópole, 2008. p.19-26. 
HAKANSON, I.; VOORHEES, W.B.; RILEY, H. Vehicle and wheel factors influencing soil compaction and crop response in different traffic regimes. Soil and Tillage Research, v.11, p.239-282, 1988.

HUANG, S.; PENG, X.X.; HUANG, Q.R.; ZHANG, W.J. Soil aggregation and organic carbon fractions affected by long-term fertilization in a red soil of subtropical China. Geoderma, v.154, p.364-369, 2010.

IMHOFF, S.C. Indicadores de qualidade estrutural e trafegabilidade de Latossolos e Argissolos Vermelhos. 2002. 104p. Tese (Doutorado) - Escola Superior de Agricultura Luiz de Queiroz, Piracicaba.

KEMPER, W.D.; CHEPIL, W.S. Size distribution of aggregates. In: BLACK, C.A.; EVANS, D.D.; WHITE, J.L.; ENSMINGE, L.E.; CLARK, F.E. (Ed.). Methods of soil analysis. Madison: ASA, 1965. p.499-510.

MIELNICZUK, J. Matéria orgânica e sustentabilidade de sistemas agrícolas. In: SANTOS, G. de A.; CAMARGO, F.A. de O. (Org.). Fundamentos da matéria orgânica do solo: ecossistemas tropicais e subtropicais. Porto Alegre: Genesis, 1999. p.1-8.

OLIVEIRA, G.C.; DIAS JÚNIOR, M.S.; RESCK, D.V.S.; CURI, N. Caracterização química e físico-hídrica de um Latossolo Vermelho após vinte anos de manejo e cultivo do solo. Revista Brasileira de Ciência do Solo, v.28, p.327-336, 2004.

PEDROTTI, A.; PAULETTO, E.A.; GOMES, A. da S.; TURATTI, A.L.; CRESTANA, S. Sistemas de cultivo de arroz irrigado e a compactação de um Planossolo. Pesquisa Agropecuária Brasileira, v.36, p.709-715, 2001.

RAIJ, B. Van; ANDRADE, J.C. de; CANTARELlA, H.; QUAGGIO, J.A. (Ed.). Análise química para avaliação da fertilidade de solos tropicais. Campinas: Instituto Agronômico, 2001. 285p.

RECOMENDAÇÕES técnicas para a cultura da soja na região central do Brasil. Londrina: Embrapa Soja, 1997. 171p.

RHEINHEIMER, D. dos S.; CAMPOS, B.-H.C. de; GIACOMINI, S.J.; CONCEIÇÃO, P.C.; BORTOLUZZI, E.C. Comparação de métodos de determinação de carbono orgânico total no solo. Revista Brasileira de Ciência do Solo, v.32, p.435-440, 2008.
ROSOLEM, C.A.; CALONEGO, J.C.; FOLONI, J.S.S. Leaching of nitrate and ammonium from cover crop straws as affected by rainfall. Communications in Soil Science and Plant Analysis, v.36, p.819-831, 2005.

SALTON, J.C.; MIELNICZUK, J.; BAYER, C.; BOENI, M.; CONCEIÇÃO, P.C.; FABRÍCIO, A.C.; MACEDO, M.C.M.; BROCH, D.L. Agregação e estabilidade de agregados do solo em sistemas agropecuários em Mato Grosso do Sul. Revista Brasileira de Ciência do Solo, v.32, p.11-21, 2008.

SANTOS, H.G. dos; JACOMINE, P.K.T.; ANJOS, L.H.C. dos; OLIVEIRA, V.A. de; OLIVEIRA, J.B. de; COELHO, M.R.; LUMBRERAS, J.F.; CUNHA, T.J.F. (Ed.). Sistema brasileiro de classificação de solos. 2.ed. Rio de Janeiro: Embrapa Solos, 2006. 306p.

SEVERIANO, E. da C.; OLIVEIRA, G.C. de; DIAS JÚNIOR, M. de S.; OLIVEIRA, L.F.C. de; CASTRO, M.B. de. Pressão de preconsolidação e intervalo hídrico ótimo como indicadores de alterações estruturais de um Latossolo e de um Cambissolo sob cana-de-açúcar. Revista Brasileira de Ciência do Solo, v.32, p.1419-1427, 2008.

STONE, L.R.; SCHLEGEL, A.J. Tillage and crop rotation phase effects on soil physical properties in the West-Central Great Plains. Agronomy Journal, v.102, p.483-491, 2010.

TAIZ, L.; ZEIGER, E. Plant physiology. $3^{\text {rd }}$ ed. Sunderland: Sinauer Associates, 2002. 90p.

TAVARES FILHO, J.; BARBOSA, G.M. de C.; RIBON, A.A. Atributos físicos de Latossolo distrófico psamítico sob diferentes usos agrícolas. Revista Brasileira de Ciência do Solo, v.34, p.925-933, 2010.

TENNANT, D.A. A test of a modified line intersect method of estimating root length. Journal of Ecology, v.63, p.995-1001, 1975.

YODER, R.E. A direct method of aggregate analysis of soils and a study of the physical nature of erosion losses. Journal of American Society of Agronomy, v.28, p.337-351, 1936.

ZONTA. E.; BRASIL, F. da; GOI, S.R.; ROSA, M.M.T. da. O sistema radicular e suas interações com o ambiente edáfico. In: FERNANDES, M.S. (Ed.). Nutrição mineral de plantas. Viçosa: Sociedade Brasileira de Ciência do Solo, 2006. p.7-52.

Recebido em 29 de julho de 2010 e aprovado em 3 de novembro de 2010

Pesq. agropec. bras., Brasília, v.45, n.12, p.1489-1498, dez. 2010 